\title{
Removable Urban Pavements: An innovative, sustainable technology
}

\author{
François de Larrard ${ }^{1}$, Thierry Sedran², Jean-Maurice Balay ${ }^{3}$ \\ 1. Scientific Direction - LUNAM Université, IFSTTAR (formerly LCPC) - Centre de Nantes - Route de Bouaye - \\ BP 4172 - 44341 BOUGUENAIS - France \\ Phone: 33240845638 - Fax: 332408457 08-francois.de-larrard@ifsttar.fr \\ 2. Materials Department - IFSSTAR - thierry.sedran@ifsttar.fr \\ 3.Infrastructure and Mobility Department - LCPC - jean-maurice.balay@ifsttar.fr
}

\begin{abstract}
Removable Urban Pavements: An innovative, sustainable technology By definition, a Removable Urban Pavement (RUP) can be quickly opened and closed, using lightweight equipment, for easy access to underground networks. While no such pavement appears to have ever been constructed, the premises of the concept can be found in certain military paths or industrial soils. A survey conducted among French municipal authorities has revealed the potential benefit of the RUP concept in decreasing the public nuisance caused by pavement and road network maintenance work. Two French cities, Saint Aubin-lès-Elbeuf (near Rouen, SeineMaritime, Normandy) and Nantes (Loire- Atlantique, western France) agreed to play host to an RUP experiment. A set of functional specifications was provided for streets to be built in new residential areas, subsequent to which original pavement designs were proposed based on a configuration of precast, hexagonal concrete slabs over a hydraulic base course easy to excavate. After successful trials using accelerated loading facilities, two removable structures were built and subjected to real traffic. Should the satisfactory behavior observed so far last into the future, RUPs would appear to be a highly sustainable response to the needs of modern cities.
\end{abstract}

Keywords: cement-treated material, excavation, experimental site, precast elements, sustainability, utility networks

\section{Introduction}

Urban pavements perform many functions and incorporate many types of utilitynetworks (water supply and stormwater, electricity, telecommunications, etc.). Since perfect coordination among all operators is very difficult to achieve, these pavements are prone to undergoing frequent works, in some cases soon after construction or maintenance. Such works wind up being a major disturbance to the human environment, causing noise, air pollution and traffic congestion; moreover, they exert a detrimental impact on the street's architectural harmony. For this reason, the "Ponts et Chaussées" civil engineering laboratories decided to implement an R\&D program aimed at developing a new technology: the Removable Urban Pavement [Maribas et al., 2005a, 2005b; de Larrard et al., 2006]. The central idea herein is to design a pavement capable of being opened and closed within just a few 
hours using very lightweight site equipment, in restoring the initial street appearance and all its functionalities.

Following an examination of previous research, this paper will present the results of a survey conducted among urban road authorities. Next, two RUP projects, each built in a different French city, will be detailed. Lastly, the sustainability of this new concept will be assessed, and a conclusion provided on the future of RUP.

\section{Bibliographical review}

An extensive bibliographical search was carried out at the beginning of the project [Ferrand et al., 2003]. A number of conventional and innovative techniques were identified in the literature, including:

- Paving block pavements [Abate, 1993], some of which are at least partially removable. However, the time necessary to open and close these street pavements does not match the RUP project goal (i.e. half of a work day). In addition, the behavior of such pavement systems under heavy truck traffic is seldom satisfactory, with rutting and other distresses appearing several years following construction. Experience gained in France would tend to promote mortar-bound paving blocks, yet according to such an option the pavement is obviously no longer removable;

- Pavement based on the use of large precast elements [Rollings and Chou, 1981, Merritt et al., 2002]. These elements however are generally fastened to one another and/or stuck to their base course, which therefore makes the removal operation a destructive one. An existing RUP technique was found within this category; nonetheless, in the context of industrial soils, only the surface layer needs to be removable;

- Steel plates are often used to allow for uninterrupted traffic when works are in progress on a street. However, such a solution is always limited in scope and effective on no more than a few square meters;

- Military paths composed of lightweight metal elements, which can rapidly be applied in order to allow trucks and military vehicles to travel over very soft soils. These pavements are actually removable, although their applicability to the urban environment would not be simple since they do not conform to most urban pavement specifications (e.g. evenness, skid resistance, appearance and durability). Moreover, in a civilian context, such pavements most likely become prohibitively expensive. 
As a conclusion to this brief survey, it would seem that no operational RUP technology can be found, given the concept of a pavement designed to be easily opened and closed using non-destructive techniques and suitable to a context of modern urban streets.

\section{Preliminary survey and potential market}

During the project preparation phase, some 40 municipal authorities were interviewed. The purpose of these meetings was to identify the potential advantages of RUP technology, according to an average "customer" opinion. These advantages will be listed hereafter, ordered from the most to the least significant:

(1) reduction of nuisances to both users and neighbors caused by maintenance works;

(2) ease of access to underground networks;

(3) sustainable management of the pavement (possibility of repairing or modifying pavement functions, streamlined reuse/recycling of the modular elements);

(4) possibility of building easily-maintained reservoir pavements;

(5) possibility of incorporating utility networks and instrumentation into the removable pavement itself;

(6) possibility of building permeable, noise-absorbing pavements offering easy maintenance (in a factory setting);

(7) simplification in the management of horizontal markings.

The first three items convinced the authors to pursue the project by focusing on practical applications. In the setting of contemporary urban development, four potential markets were identified through this survey:

- Downtown streets: These streets are typically characterized by a limited truck traffic, slow vehicle speeds and an intricate geometry, with high population density and a concentration of surrounding buildings;

- Boulevards and urban highways: For this segment, the planar shape of the pavement is straighter, while the traffic is more intense (higher speeds and more trucks);

- New residential areas: In this setting, new streets need to be built, allowing the shape to be designed according to pavement technology. The traffic here tends to be limited, much like for downtown streets;

- Tramway lanes (railway transit tracks): This means of transportation is growing increasingly popular in European cities. Since public transit services are intended to avoid traffic disruption to the greatest extent possible, use of a removable pavement in this instance 
would be of tremendous benefit. Moreover, a removable tramway would allow municipal authorities to leave the existing network in place, as opposed to the current technique whereby all utility networks have to be displaced prior to constructing the tramway line, which engenders an extensive and costly works program. The design of a durable tramway pavement however is still an unresolved issue, and adding a removability function would once again complicate the process.

The authors are well aware of the existence of more elegant solutions for easily accessing utility networks, notably multipurpose utility tunnels [Clé de sol, 2005]. Yet such solutions are only feasible on major projects where many networks need to be built simultaneously. As another alternative, removable sidewalks could be envisaged, and a number of examples are already in service in some industrial areas; however, this solution proves inadequate when utility networks cross a street.

On the basis of these general ideas, partnerships were sought with municipal authorities interested in setting up experimental RUP sections. Two cities accepted to participate in this effort and proposed streets in new residential areas, which was the least difficult setting among the four possible markets listed above [de Larrard, 2009].

\section{The Saint Aubin project}

Saint Aubin-lès-Elbeuf is a city of approximately 8,500 population, located near the Rouen metropolitan area within France's Seine-Maritime Department (Normandy). Saint Aubin has a long tradition of civil engineering innovation and was the first city to agree to build an RUP within the framework of the present project. The reasons behind the Saint Aubin authorities' decision to join the project were as follows:

- the identified need to push for innovation in urban works;

- a goal to decrease the social pressure induced by civil engineering works in the urban environment;

- sustainable aspect of the RUP concept, which promotes material recycling.

Moreover, Saint Aubin was interested in entering into a PPP (Public-Private Partnership) dedicated to building an RUP since many local stakeholders could benefit from such technology (utility companies, the cement industry, etc.). The opportunity was provided by the reconstruction underway in the Manopa district, a former industrial zone being rehabilitated as a residential area. 


\section{Specifications and design}

The street to be built was 90-m long. After discussions held between road authorities and the various utility operators, a set of specifications was written (see Table 1 for details). Due to the dimensions of the selected modular elements, the option of using precast concrete slabs was quickly adopted. Regarding slab shape, hexagons were chosen over rectangles to reduce the risk of angle failure.

The slabs had to be mechanically independent to be easily lifted during maintenance operations. As for the joints, the initial notion was to use sand, like in a classical paver design. However, the density of this sand would have increased over time due to water infiltration and urban sediments. The risk was then introduced of strong friction countering the easy lifting of slabs upon removal. A soft, cold and waterproof polymeric material, easy to remove manually, was therefore cast into the joints. As is the case with some conventional modular pavements, the slabs were placed over a granular bed so as to simplify element positioning.

Though the base course served a structural purpose, network operators expressed the preference for use of an easy-to-dig material. A new material, called Structural Excavatable Cement-Treated Material (SECTM), was thus added to the specifications. Three-dimensional finite element computations were carried out to evaluate the stresses induced by traffic in both the slabs and base course. The allowable stresses were determined according to the classical French pavement design fatigue approach [LCPC-SETRA 1994]; as a final step, the minimum slab and base course thicknesses were calculated. Like for plain concrete slabs, a high level of safety was sought, in order to avoid the risk of failure under traffic loads as well as during removal / replacement operations. These considerations resulted in a 200-mm thickness, except around the edges where an additional thickness of $10 \mathrm{~mm}$ was introduced to ensure good contact between the slab and the granular bed. These computations led to a total thickness of $600 \mathrm{~mm}$ for the base course, which consisted of two 300-mm layers of structural cement-treated material (see next section). This thickness however was derived from standard application of the French design method, which has been validated for stronger materials. It is likely that this $600-\mathrm{mm}$ thickness reflects an overly conservative result. Additional investigations will be carried out in the future, with the aim of reducing the base course thickness. The structural layout of the Saint Aubin project is shown in Figure 1, with hexagons fitting into a circle of radius $1,540 \mathrm{~mm}$. These dimensions were compatible with both the structural specifications and the street width.

\section{Development of a Structural Excavatable Cement-Treated Material (SECTM)}

The most innovative aspect of the Saint Aubin RUP probably lies in the composition of the base material. Required here is a structural material, as characterized by a tensile strength, Young's modulus, etc., that can be easily excavated with lightweight equipment. In France, self-compacting 
materials (sometimes called Controlled Low Strength Materials, or CLSM, in the United States) are commonly used to fill trenches, as indicated in a national guide [Bonnet et al., 1998]. The critical property of these materials is their compressive strength, which must not exceed $2 \mathrm{MPa}$. In the case of a new RUP however, the property of self-compactability is not required and moreover the use of such a material for the total volume of a base course is not economically sustainable. A new material therefore had to be developed.

Logic dictated choosing a compacted, cement-treated material as the type of granular material that makes the most efficient use of cement. Quicker strength development was also desirable, to allow for a rapid opening to traffic while avoiding a long-term strength gain that would interfere with subsequent excavation works. The decision was made therefore to design the mixture by blending Portland cement with limestone filler, while excluding pozzolans, fly ash and all types of slowhardening binders. The mixtures were optimized according to the LCPC approach [de Larrard, 1999], with the only variable parameter being the proportion of cement in the binder. Three mix designs were obtained; Table 2 lists their respective characteristics. Trial slabs with a 400-mm thickness were installed and compacted at LCPC Nantes; these specimens were then subjected to excavation tests at 7, 28 and 230 days (see Fig. 2). The CTM2 mix was ultimately selected as the material offering an acceptable compromise between strength and excavatability.

Based on the results of this study, specifications for the Saint Aubin SECTM were adopted as follows: a 28-day compressive strength of less than $2.5 \mathrm{MPa}$, and a 28-day splitting tensile strength above $0.16 \mathrm{MPa}$.

\section{RUP structure trials using the LCPC accelerated load testing facility}

From Table 1, the RUP structure is expected to resist up to 120,000 standard truck trips. Given the innovative features inherent in this structure, the underlying concept was validated, and it was decided to verify the thickness design by use of LCPC's accelerated load testing facility located in Nantes. An experimental RUP pavement comprising 19 slabs and 4 slab halves was thus built and tested on the LCPC carrousel. The fatigue test was performed according to the French standard load configuration (i.e. a twin-wheel assembly loaded at $32.5 \mathrm{kN} /$ wheel), with a linear speed of $40 \mathrm{kph}$. The test set-up is shown in Figure 3. The slabs were positioned over a $30-\mathrm{mm}$ thick granular bed spread on a 380-mm base course composed of a material resembling CTM3 in Table 2. It was later recognized that this material was too strong to be easily excavated.

At this point, several series of tests were necessary in order to:

- determine a suitable method for placing the slabs; 
- optimize the slab shape. The contact between slabs and the granular bed was found to be critical, along with a need to favor the edge zone over the central zone. A lack of contact within the perimeter zone would thus facilitate a swing motion in the slab each time the wheel passed. To ensure this peripheral contact, a 10-mm over-thickness was introduced over a 100-mm wide band around the bottom face of the slabs, hence creating a void under each modular element (see Fig. 1);

- $\quad$ select a suitable material for the granular bed. Initial tests were conducted with a classical 2$4 \mathrm{~mm}$ crushed material, yet the internal friction of this material was too sensitive to water: as water was being sprayed on the pavement, the slabs quickly displayed significant cracking. Furthermore, this level of cracking could be kept under $2 \mathrm{~mm}$ with a 6-10 $\mathrm{mm}$ crushed material, which also provided for better drainage;

- identify an appropriate solution for the joints between slabs. The first joints tested were rubber prefabricated joints, and these tended to be extracted whenever the model was subjected to the fatigue test. Such a phenomenon did not occur with a cold, cast-in-place polymeric joint.

Once these preliminary tests had been completed, the structure depicted in Figure 1 underwent testing with a SECTM that was stronger than actually necessary (as determined according to subsequent tests). No failure or other damage was detected on any slab or on the base course. The surface layer was exposed to an overall settlement of 5-8 $\mathrm{mm}$. Vertical displacements, caused by the passing of the $65-\mathrm{kN}$ standard load, were measured before the test, after 50,000 cycles and at the end of the test; these measurement results are shown in Figure 4. It can be observed that the structure is relatively stable; moreover, the loading cycles tended to decrease the level of vertical displacement. After the full series of cycles, all displacements were less than $1.5 \mathrm{~mm}$ (under the twinwheel $65-\mathrm{kN}$ load), which seems to be an acceptable value, especially in the context of a residential area with moderate vehicle speeds. It should be pointed out that little noise was produced by the subsidence motion of slabs, as the polymeric joints likely dissipated a portion of the energy.

Another loading program was then applied to the structure with a new SECTM material complying with the specifications previously announced. The behavior was identical, with limited cracking of the slabs. Furthermore, after completing 120,000 cycles, the slabs were removed and the base course could be observed. Neither cracking nor any other type of damage was detected. It was ultimately concluded that the RUP structure had been validated through this full-scale study.

On the basis of these successful test results, a call for tender was launched for the construction of an RUP in Saint-Aubin. The SCREG company was selected, and design studies were undertaken with the aim of producing slabs in a prefabrication plant as well as SECTM in a central plant. The RUP was actually built in 2007. 


\section{The Saint Aubin construction site}

Figure 5 presents the layout of the St Aubin RUP, while Figure 6 highlights the site's most significant phases, which took place during summer 2007. The construction process ran smoothly since most individual technical actions entailed use of state-ofthe- art urban pavement technology. The SECTM production task raised some concerns with project partners. Given the very low cement dosage of the mix (approx. $25 \mathrm{~kg} / \mathrm{m3}$ ), the need for effective dosage control during production had to be addressed. Preliminary tests were carried out with a specially blended cement containing $10 \%$ Portland cement and $90 \%$ limestone filler. Even in this solution however, a fine-tuned control of the Portland cement dosage did not seem to be any easier; hence, the SECTM was eventually produced from separate powders. Otherwise, the contractor observed that the time required to cast joints with the polymeric material was longer than expected, yet the use of prefabricated joints had been excluded, following negative test results during the LCPC trials.

Once the street construction phase was complete, a quality control inspection performed both during and after the works led to the following conclusions:

- Negative findings: The rigidity of roughly half the surrounding platform was less than the required value; the SECTM compressive strength often exceeded the maximum value of 2.5 $\mathrm{MPa}$ (with individual values varying from 2.1 to $3.1 \mathrm{MPa}$ ); while the strength of the slab surface concrete remained in the low range of a typical pavement concrete. These control results however were not reflected by performance defects, except for some gravel losses at the surface of concrete slabs under traffic loads;

- Positive findings: The control of cement dosage in the SECTM proved satisfactory (the requested mean value of $1.1 \%$ was matched with a standard deviation on the order of 0.05\%). It is therefore considered that the excess SECTM strength was probably due to the higher cement strength, relative to the cement supply used in the laboratory mix-design study. The skid resistance of the exposed aggregate concrete surface of slabs was well above the specified value of 0.45 (obtained from the SRT pendulum measurement, according to the NF P 98 831-4 Standard). As regards slab dimensions, all requirements (e.g. thickness or distance between apexes) were met. The street evenness was deemed to be excellent, and the cracking between adjacent slabs under heavy vehicle loads remained within an acceptable range, i.e. similar to that obtained during the preliminary LCPC trials (mean value: $0.7 \mathrm{~mm}$, standard deviation: $0.65 \mathrm{~mm}$, maximum value: $2.5 \mathrm{~mm}$ with $90 \%$ of values less than $1.7 \mathrm{~mm}$ ). 
Several months after completing construction, the St Aubin RUP was opened and closed (see Fig. 7). The joints were cut and removed manually, then the slabs were lifted with a vacuum lifting device. The base material was easily excavated with a hydraulic excavator. These tests served to verify the soundness and operability of the RUP concept.

\section{The Nantes project}

\section{Specifications}

In Nantes, a new street in an existing residential area was proposed by municipal authorities to experiment the RUP concept. At this site, the expected traffic levels were even lower than in Saint Aubin (approx. 10,000 heavy truck trips over the life of the pavement). The main difference in specifications (see Table 1), in comparison with the Saint Aubin project, pertains to slab dimensions. With smaller slabs, the effect of stress diffusion from truck wheels to the base course is minimized. Designers thus considered that the option of mechanically-independent slabs was no longer viable for this project.

\section{Envisaged solutions}

Two solutions were studied in detail. In the first one, "semi-independent" slabs were chosen; this solution entailed placing the slabs on recycled wood beams, whose purpose was to avoid the occurrence of joint cracking steps due to granular bed settlement. This structure was tested at the CER Road Test Center in Rouen and found easy to construct and then remove. Under light vehicle loads, the resulting behavior was found to be satisfactory; however, in the presence of heavy truck traffic, the slabs tended to subside by several centimeters. This problem might have been solved by changing the material inserted between the concrete and wood (in this instance, a geotextile). Unfortunately, the time allocated was insufficient to optimize the system, and as a result the second solution was selected.

This second system consisted of connecting the slabs with one another by using concrete keys (see Fig. 8). The structure was designed at LCPC's facilities, and a 160- mm thickness was initially proposed for the slabs. A model comprising 31 slabs was built and tested by the Autun Regional Laboratory (LRA). It was then subjected to 1,290 trips made by a deflectometer-mounted truck (French standard device for deflection measurements, equipped with a $130-\mathrm{kN}$ single rear axle), which reproduced the effects of heavy truck travel.

This test induced a number of distresses: three connection keys failed under shear forces, and a slab angle was crushed. Based on these results, the structure was redesigned in introducing 3D finite 
element modeling: the slab thickness was increased to $190 \mathrm{~mm}$ and steel fibers were added into the concrete mix formulation so as to decrease the likelihood of fracture and facilitate the removal process, in those cases where cracking could appear.

\section{The Nantes construction site}

Since this new design had not been tested under actual traffic conditions, the City of Nantes decided to build a new $12 \times 7 \mathrm{~m}$ model, corresponding to approximately 155 slabs, within an industrial zone near a material storage area and exposed to heavy truck traffic. The corresponding pavement structure is presented in Figure 9; it has been assembled from a combination of hexagonal slabs with concrete keys. Such a pavement pattern can obviously only be built by successive lines, progressing from one edge to the other. The slab arrangement is surrounded by simple, parallelepipedshaped concrete paving blocks, which serve to both block the system horizontally and allow for pad removal by means of sliding and lifting the slabs (Fig. 10).

Although application of the normal French design approach would have led to a thicker base course, the project owner decided to limit this value to $0.40 \mathrm{~m}$. As regards the granular bed, the requirement for internal friction was not as stringent as in the St Aubin RUP due to the presence of concrete keys between the slabs. On the other hand, the need to slide the slabs horizontally during placement led to selecting a rounded aggregate with a size ranging from 2 to $4 \mathrm{~mm}$. The joints between slabs were filled with ordinary sand, as is typical in pavement construction. As opposed to the independent slab concept applied in St Aubin, slab removal here induced horizontal displacement, meaning that the internal friction of the sand could not resist the easy lifting of slabs.

The project was built during summer 2008. As was the case at the St Aubin site, a portion of the platform did not conform to the specified stiffness. The SECTM was produced in a ready-mix concrete plant, and both the composition and properties obtained were close to matching the requirements. Moreover, the air-entrained, steel fiber concrete used to produce the precast slabs displayed the required compressive strength. The only surprise for the contractor was the time necessary to mount the slabs: the need for minimum clearance between male and female parts had been disregarded during the system design phase. Consequently, many slabs had to be planned onsite, requiring the use of a portable saw. Once the dimensions had been corrected however, slab mounting with a vacuum lifting device appeared to be very quick and straightforward. A fixed underground service outlet was set in the middle of the pad before beginning RUP construction in order to demonstrate concept compatibility with the presence of such singular points. The outlet was surrounded by a paver line, and the slabs were sawn onsite to complement the arrangement around the outlet. The pad appearance was deemed satisfactory by the owner (Fig. 11). 
A few weeks after the end of construction, a technical meeting was held for professionals involved in the project, and an opening-closing sequence of the pavement was featured (Fig. 12). This operation could be carried out with ease. Due to the interlocking slabs, it was necessary to first remove a paver line then the edge slabs, in progressing towards the central zone. Yet this constraint seems to be compatible with the requirement of performing maintenance in less than half a day. After being exposed to roughly one year of traffic loads, the Nantes RUP exhibited satisfactory behavior, with very little cracking under heavy truck loads and no perceptible related noise emissions.

\section{Assessment of concept sustainability}

The shift to removable pavements would be a drastic change in contemporary urban design; as such, a careful examination of all aspects would be needed to convince municipal authorities to adopt this innovative approach. A 10 to 20 -year feedback cycle would of course be a necessary step to perform a strict assessment, while fullscale testing had only been started 1 or 2 years prior at the time of reporting on results. Nonetheless, the following preliminary analysis can still be proposed in the European context [CUD, 2008].

\section{Life-cycle cost}

An evaluation of the life-cycle cost was conducted for the two experimental pavements built within the framework of the present project. The RUP cost was compared to that of a Conventional Urban Pavement (CUP), which is composed of an untreated granular material layer covered by a thin asphalt concrete wearing course. A 30-year lifespan was considered for this assessment. The lifecycle cost is the sum of: the initial construction cost, the cost incurred by opening/closing the pavement to access the networks (also called the "network maintenance cost"), the pavement maintenance cost (to lay a new wearing course), and lastly an external social cost.

The initial costs were evaluated by summing the typical costs associated with the basic construction steps. As already pointed out therefore, RUPs are based on a nonstandard combination of standard individual tasks, such as building a base course with cement-treated material and producing precast concrete slabs. Project owners are provided access to databases containing mean values for such basic tasks. By summing these costs, the typical RUP construction cost could be derived, in the event such a technology were to be disseminated.

Regarding network costs, it has been assumed that one-third of the pavement surface area is opened over the course of the pavement lifespan. Each pavement opening task would result in a certain cost, proportional to the duration of the task. This duration was set at 2.5 days for a CUP, compared to 0.5 
day for an RUP. Only the civil engineering costs were taken into account in this calculation (utility network repairs were excluded from these calculations).

As for the pavement maintenance cost, it was assumed that the CUP wearing course needed to be changed one time over the pavement lifespan, while the concrete slabs could last longer with nearly no maintenance operation, except for joint renewal. Inclusion of the social cost appeared to be a more delicate step (see the next section). Only a portion of this social cost was in fact considered, i.e. the cost borne by local shops, which experienced a decline in their sales revenue during the street works. An amount of $€ 200 /$ day was assigned for a single shop; in all, five shops were impacted when digging the trench.

The outcome of these calculations is illustrated in Figure 13 for both the St Aubin and Nantes projects, respectively. According to these values, the following preliminary conclusions can be drawn:

- In terms of initial cost, an RUP is three to four times more expensive than a CUP, though it should be noted that the considered CUP technique is among the cheapest. In many cities or even villages where authorities emphasize architectural-friendly techniques for their streets, higher quality materials like traditional pavers or stone slabs are used, causing pavement construction budgets to become roughly comparable to the initial cost of an RUP;

- When combining initial costs and maintenance costs, the CUP and RUP budgets tend to be quite comparable;

- Accounting for just a portion of the social cost clearly favors the RUP solution.

\section{Social impacts}

For various categories of stakeholders, RUP implementation may have positive consequences, i.e.:

- Pavement users are concerned by traffic interruptions caused by the street works. In retaining the same hypotheses as for the economic calculations and assuming a 100-m long street section, the total number of days traffic is interrupted over the pavement lifespan equals: 46 in the case of CUP, vs. just 8 for an RUP;

- Project neighbors are exposed to noise, vibrations and dust emissions induced by the associated public works. In the case of an RUP, a double benefit will be derived: less disturbance due to the absence of demolition jackhammers and other noisy devices; plus a much shorter average works duration;

- The use of precast elements tends to decrease the amount of outdoor works required and increase the work performed inside the factory, where health and safety conditions can be better controlled, such that workers will also benefit from RUP implementation; 
- All urban residents are sensitive to the appearance of pavement, which makes up part of their familiar landscape. Less conspicuous maintenance work and the absence of visible scars on the road will make cities more pleasant environments for the general public;

- Lastly, public works engineers will encounter fewer citizen complaints and a smaller workload due to the decreased frequency of pavement maintenance. Moreover, an RUP can be easily adapted to a functional change, such as the creation of a pedestrian area for a special event.

\section{Environmental impacts}

The RUPs developed in this project are primarily based on the use of hydraulic materials: concrete for the slabs, and a cement-treated material for the base course. The use of oil-based materials has been minimized. The decrease in traffic interruptions has also lowered gas consumption, which makes this technology favorable to the conservation of non-renewable resources.

During maintenance operations, waste production is also minimized since the wearing course is simply removed and replaced. It can even be anticipated that the dismantled SECTM material can be recycled into a controlled low-strength material [Recycan, 2010]. If such were the case, next to no waste would be produced.

As far as carbon dioxide emissions are concerned, the RUP solution might appear less attractive, due to the heavier weight of Portland cement being input. However, this calculation also needs to account for both the reduction in traffic disruption and slab durability, potentially yielding a much longer lifespan than the 30-year design.

Conclusion A new urban pavement concept has been developed within the scope of a partnership involving various French organizations, including research laboratories, municipal owners, material producers and contractors: the Removable Urban Pavement. The decision to launch this project was made after conducting a survey that confirmed the potential interest of this RUP concept on the part of municipal owners. Two cities agreed to host an experiment consisting of site selection and a set of functional specifications.

Two technologies, based on the use of precast concrete slabs supported by a Structural Excavatable Cement-Treated Material (SECTM), were developed herein. According to the first, the slabs are mechanically independent, while in the second the slabs are interlocked. These innovative technologies were then validated through accelerated tests and experimental site conditions. Through a preliminary examination of economic, social and environmental aspects, RUPs would appear to be highly sustainable. 
A technical guide was produced by project partners [CUD, 2008] to provide assistance to cities in drawing up RUP specifications. Contractors can also find in this document critical technical recommendations to ensure successful implementation. Project partners will continue to monitor the existing RUPs in order to confirm the validity of the design as well as the satisfactory in situ behavior.

Acknowledgments: The authors are grateful to the cities of St Aubin-lès-Elbeuf and Nantes, as well as all project partners for their strong commitment to this project. Special thanks are also addressed to the French Ministry of Public Works (now MEDDTL), the Seine-Maritime Departmental Council and CIMBETON for their financial support.

\section{REFERENCES}

Abate M.K., 1993. Concrete Paving Blocks : An Overview. Final Technical Report, Washington State Transportation Center, WA-RD 319.1, 75 p.

Bonnet G., Gavalda A., Quibel A., 1998. Remblayage de tranchées - Utilisation de matériaux autocompactants. Dossier CERTU N 78, 36 pages, April, in French.

Clé de Sol, 2005. Guide pratique des galeries multiréseaux - Clé de Sol. Collection Dossiers d'experts, Editions Techni-Cités, 225 p., April, in French.

CUD, 2008. Chaussées Urbaines Démontables - Guide Technique 2008. Technical guide, published by CERTU, December, in French.

de Larrard F., 1999. Concrete Mixture-Proportioning - A Scientific Approach. E \& FN SPON, London, $440 \mathrm{p}$.

de Larrard F., Balay J.M., Sedran T., Laurent G ., Leroux A., Maribas J ., Vulcano-Greullet N., Sagnard N., Masson J.M., Belouard R., 2006. Development of a removable urban pavement technology. 10th International Symposium on Concrete Roads, Brussels, September 18-22.

de Larrard F. (ed.), 2009. Expérimentations sur les chaussées urbaines démontables, Etudes et recherches des LPC, EG 22, 138 p., June, in French.

Ferrand J., Duffait J., Josserand L., de Larrard F., 2003. Les chaussées urbaines démontables - Etude bibliographique. Internal LCPC report, 39 p., December, in French.

LCPC-SETRA, 1994. Conception et dimensionnement des structures de chaussées. Guide technique. SETRA - Paris, December, in French.

Maribas J., Petit G., Sedran T., Kerzreho J.P., Balay J.M., de Larrard F., 2005. Développement de chaussées urbaines démontables. Congrès Ingénierie Urbaine - Technologies innovantes pour les infrastructures et l'habitat, Lille, October, in French. 
Maribas J., Vulcano-Greullet N., de Larrard F., 2005. Un accès aux réseaux par des chaussées urbaines démontables. Revue Générale des Routes, º 834, pp. 74-76, January, in French.

Merritt D. K., McCullough F. B., Burns N.H., 2002. Texas Tests Precast For Speed and Usability. Public Roads - July/August.

Recycan, 2010.<http://www.eurovia.com/en/produit/128.aspx>

Rollings R. S., Chou Y. T., 1981. Precast Concrete Pavements. Report of Army Engineer Waterways Experiment Station, Vicksburg Ms Geotechnical Lab, A208801, 66 p., November. 
TABLES

Table 1: Specifications adopted for the RUPs

\begin{tabular}{|c|c|c|c|}
\hline $\begin{array}{c}\text { Set of } \\
\text { specifications }\end{array}$ & Consideration & St Aubin & Nantes \\
\hline General & Street dimensions & Straight line, $90 \times 7 \mathrm{~m}$ & $\begin{array}{l}\text { Straight line, } 86 \times 7 \mathrm{~m}+ \\
20 \times 13 \mathrm{~m} \text { square }\end{array}$ \\
\hline \multirow{2}{*}{ project } & Joints & Possible & "1" \\
\hline & Color, appearance & $\begin{array}{l}\text { Surface material should be } \\
\text { versatile (i.e. easily adapted to } \\
\text { the urban environment) }\end{array}$ & "1"1 \\
\hline \multirow{4}{*}{$\begin{array}{c}\text { Basic } \\
\text { pavement } \\
\text { specifications }\end{array}$} & Subbase layer & $\begin{array}{l}\text { PF2, according to the French } \\
\text { pavement design method } \\
\text { (Young's modulus } \geq 50 \mathrm{MPa} \text { ) }\end{array}$ & (1"1" \\
\hline & Traffic (site construction phase) & $\begin{array}{l}50 \text { heavy trucks/day, } \\
\text { total of } 20,000 \\
\end{array}$ & 10 heavy trucks/day \\
\hline & Traffic (service phase) & $\begin{array}{l}10 \text { heavy trucks/day, } \\
\text { total of } 100,000 \\
\end{array}$ & 1 heavy truck/day \\
\hline & $\begin{array}{l}\begin{array}{l}\text { Structural life span, probability } \\
\text { of failure }\end{array} \\
\end{array}$ & 30 years, $5 \%$ & 30 years, $10 \%$ \\
\hline \multirow{10}{*}{ Removability } & $\begin{array}{l}\text { Portion of the pavement to be } \\
\text { removed }\end{array}$ & \begin{tabular}{|l|} 
The entire street, \\
without sidewalks
\end{tabular} & "'"' \\
\hline & $\begin{array}{l}\text { Maximum dimensions of the } \\
\text { modular elements }\end{array}$ & $2 \mathrm{~m}$ & $0.5 \mathrm{~m}^{2}$ \\
\hline & Maximum load upon removal & $\begin{array}{l}1,000 \mathrm{~kg} \text { (unit weight of } \\
\text { elements } \leq 800 \mathrm{~kg} \text { ) }\end{array}$ & $200 \mathrm{~kg}$ \\
\hline & \begin{tabular}{|l} 
Minimum weight of the \\
modular elements \\
\end{tabular} & $100 \mathrm{~kg}$ & "1"' \\
\hline & $\begin{array}{l}\begin{array}{l}\text { Fastening technique during } \\
\text { removal }\end{array} \\
\end{array}$ & Vacuum technique & "1"' \\
\hline & $\begin{array}{l}\text { Duration of the opening/closing } \\
\text { sequence }\end{array}$ & $\begin{array}{l}\text { Opening: } 30 \mathrm{~min} \\
\text { Closing (base and top layers): } \\
4 \text { hours }\end{array}$ & $\begin{array}{l}\text { Half-day (plus network } \\
\text { maintenance) }\end{array}$ \\
\hline & $\begin{array}{l}\text { Type of material used for base } \\
\text { course repair }\end{array}$ & $\begin{array}{l}\text { Self-compacting, cementitious } \\
\text { material (controlled low- } \\
\text { strength material) }\end{array}$ & "1"' \\
\hline & Trench width & $0.40 \mathrm{~m}-2 \mathrm{~m}$ & \\
\hline & Minimum network depth & $0.60 \mathrm{~m}$ & $0.70 \mathrm{~m}$ \\
\hline & Maximum network depth & $1.50 \mathrm{~m}$ & $2 \mathrm{~m}$ \\
\hline
\end{tabular}

\section{Table 2: Mix design and properties of the three SECTMs}

\begin{tabular}{|l|c|c|c|}
\hline Formulation & CTM1 & CTM2 & CTM3 \\
\hline Cement dosage (mass \%) & 0.5 & 1.1 & 1.7 \\
\hline Specific gravity (dry) & 2.24 & 2.35 & 2.23 \\
\hline 28-day compressive strength (MPa) & 1.0 & 2.2 & 3.4 \\
\hline 28-day splitting tensile strength (MPa) & 0.07 & 0.18 & 0.31 \\
\hline Young's modulus at 28 days (MPa) & 1,600 & 4,800 & 7,800 \\
\hline Number of shovel strokes to excavate 400 mm (at 28 days) & 3 & 23 & $>40$ \\
\hline
\end{tabular}




\section{FIGURES}

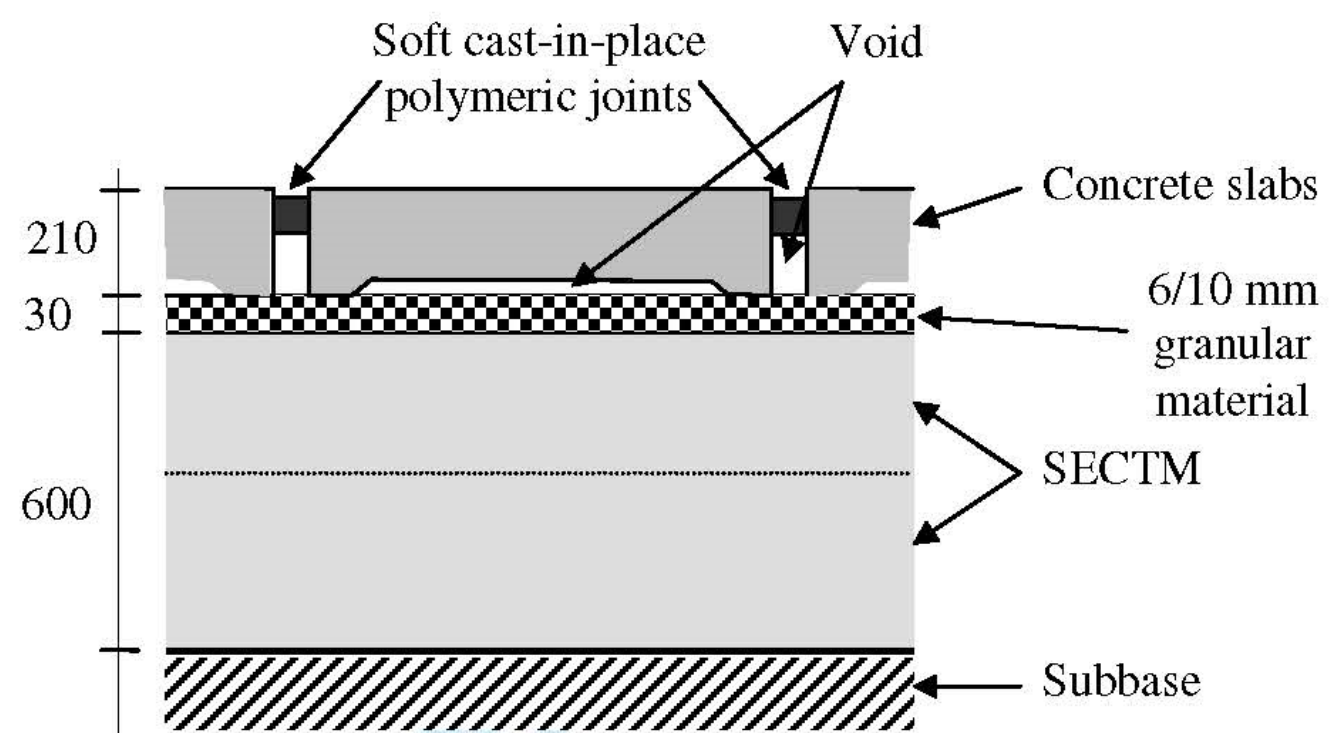

Figure 1: The Saint Aubin RUP design (dimensions are expressed in mm) 


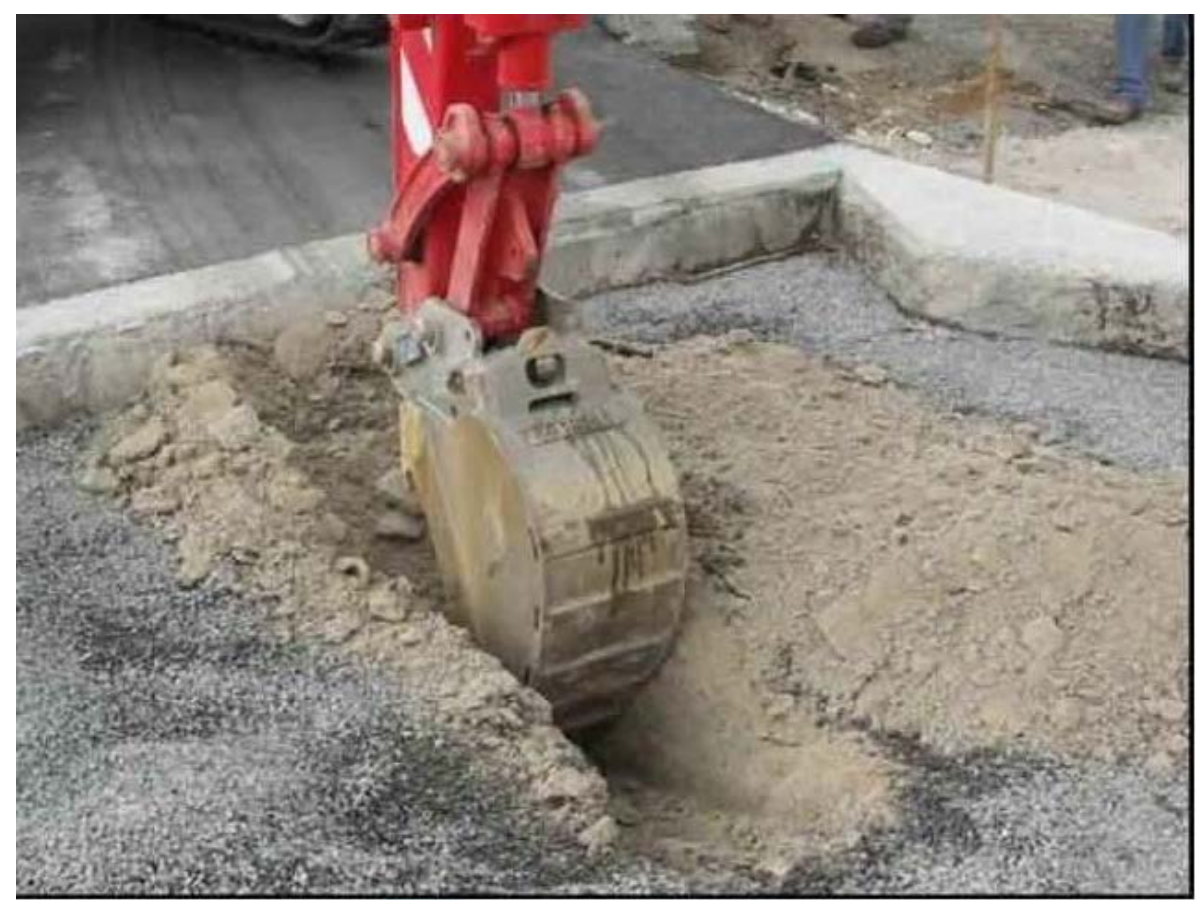

Figure 2: Excavation of the SECTM base course

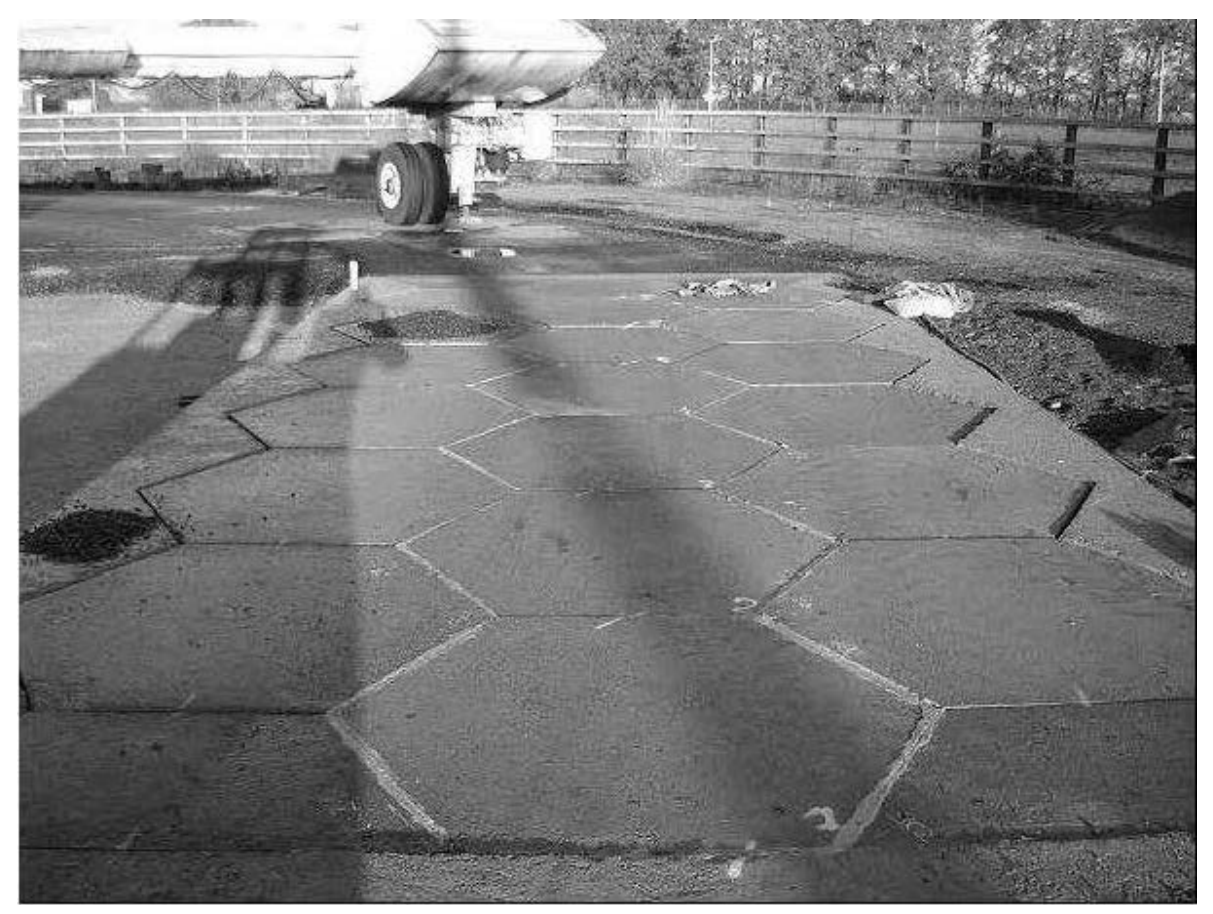

Figure 3: View of the trial set-up 


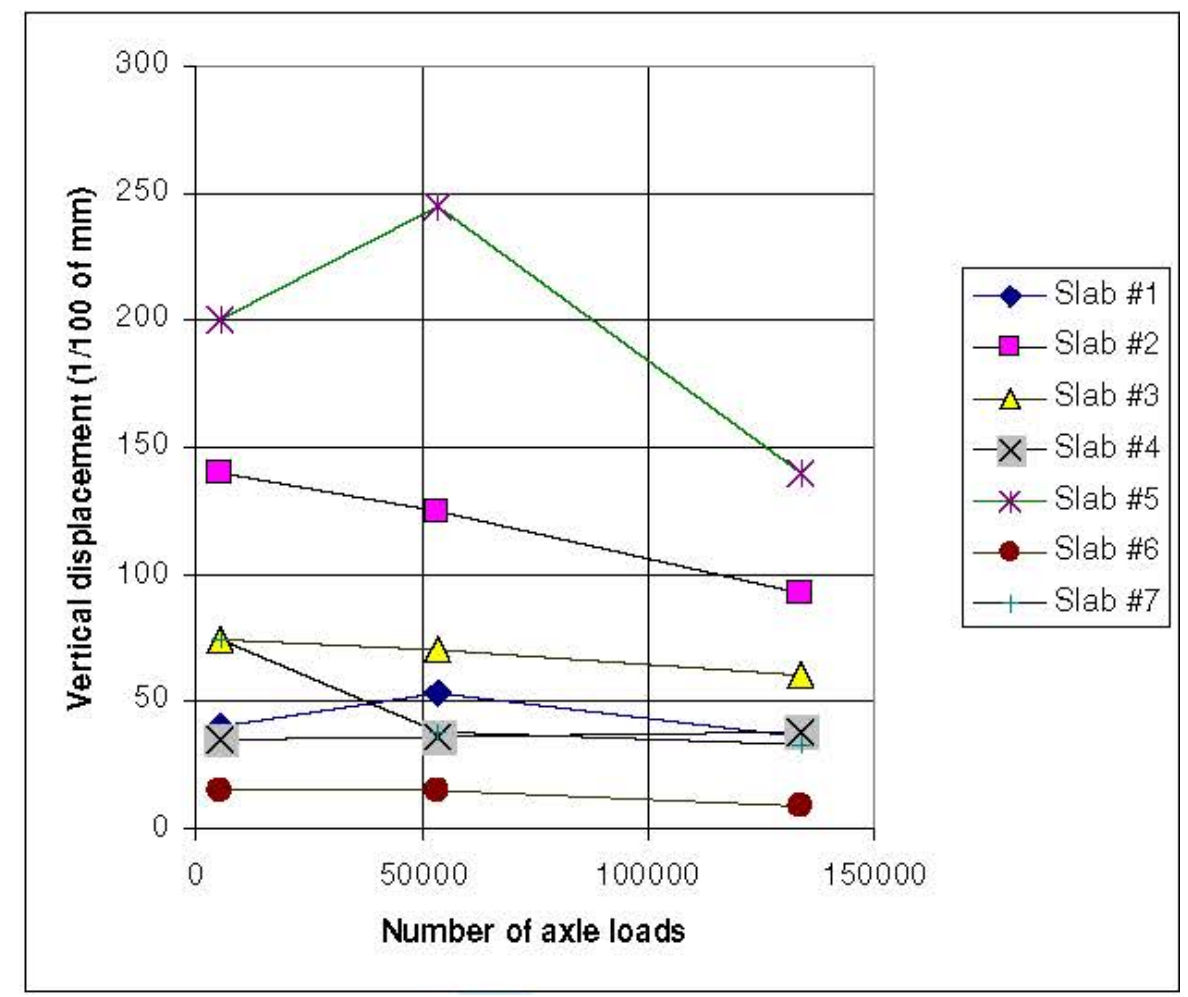

Figure 4: Vertical displacement of the central slabs vs. number of fatigue loadings

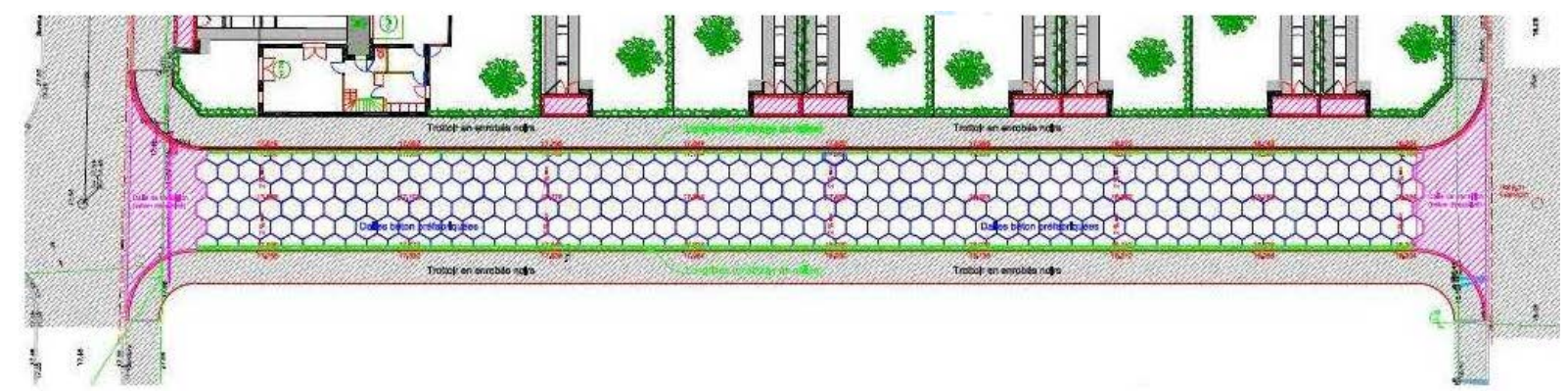

Figure 5: Layout of the Saint-Aubin RUP 

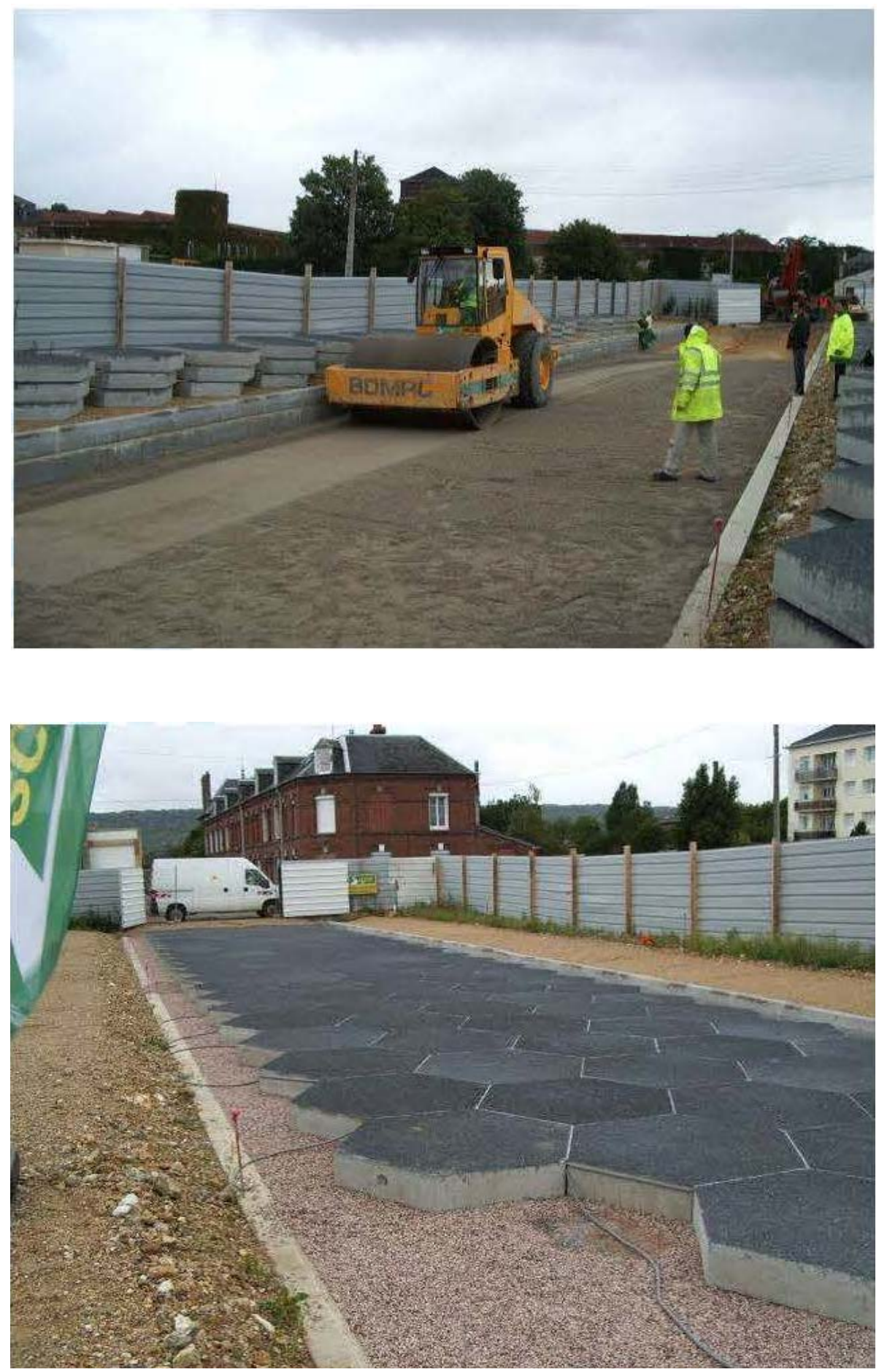

Figure 6: Construction of the Saint Aubin RUP 

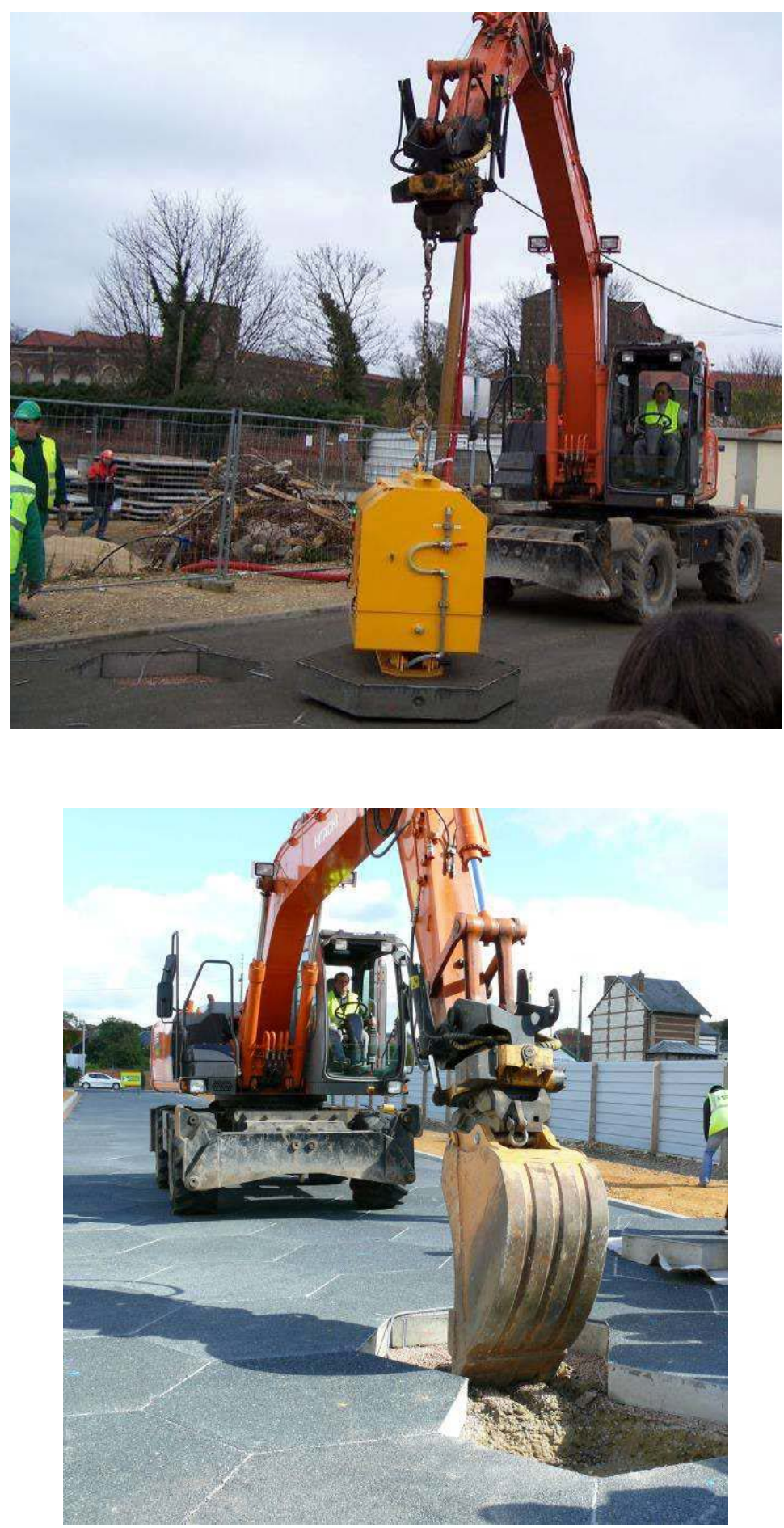

Figure 7: Opening of the Saint Aubin RUP 

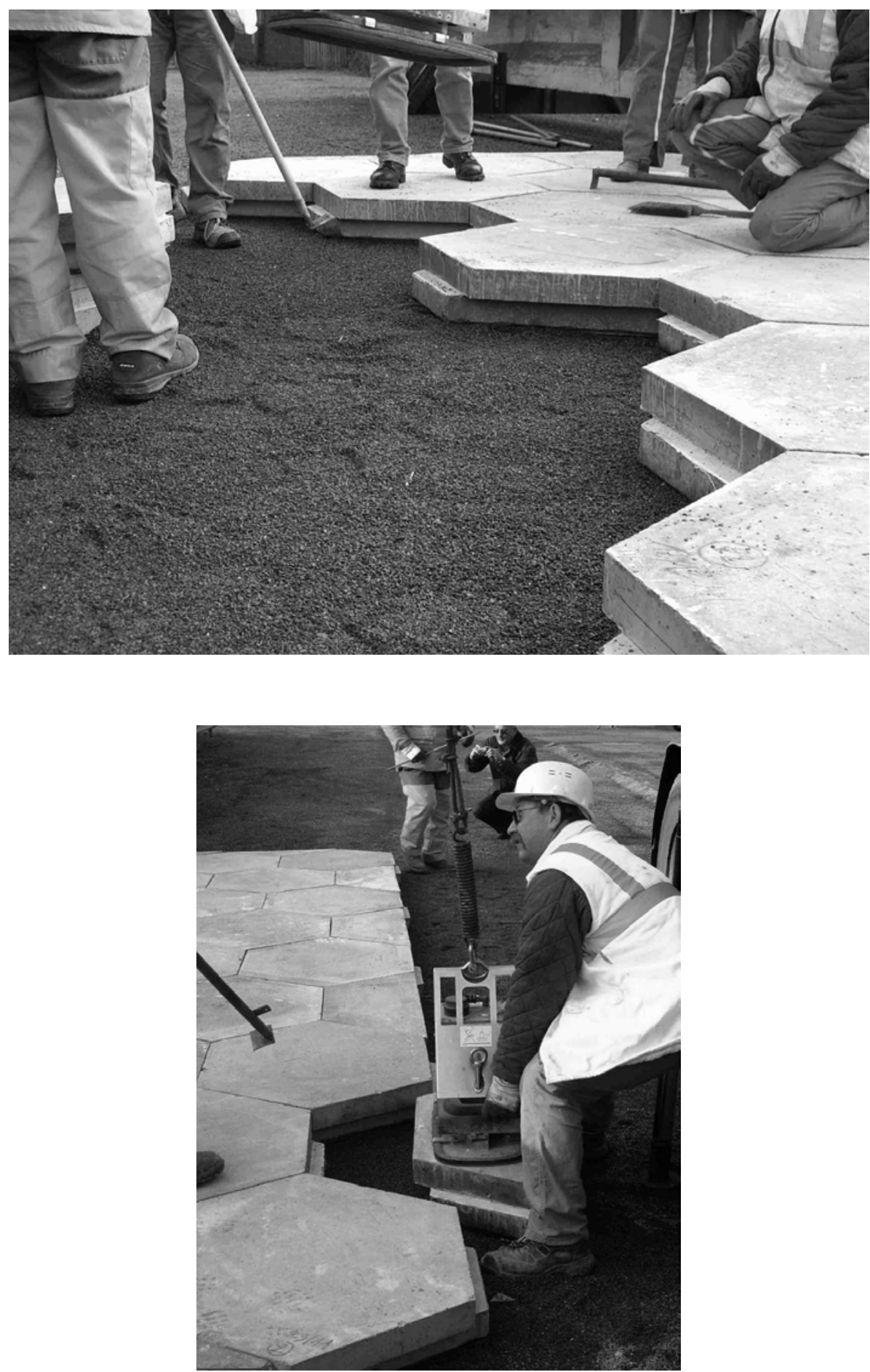

Figure 8: The Autun solution (slabs with connection keys) 


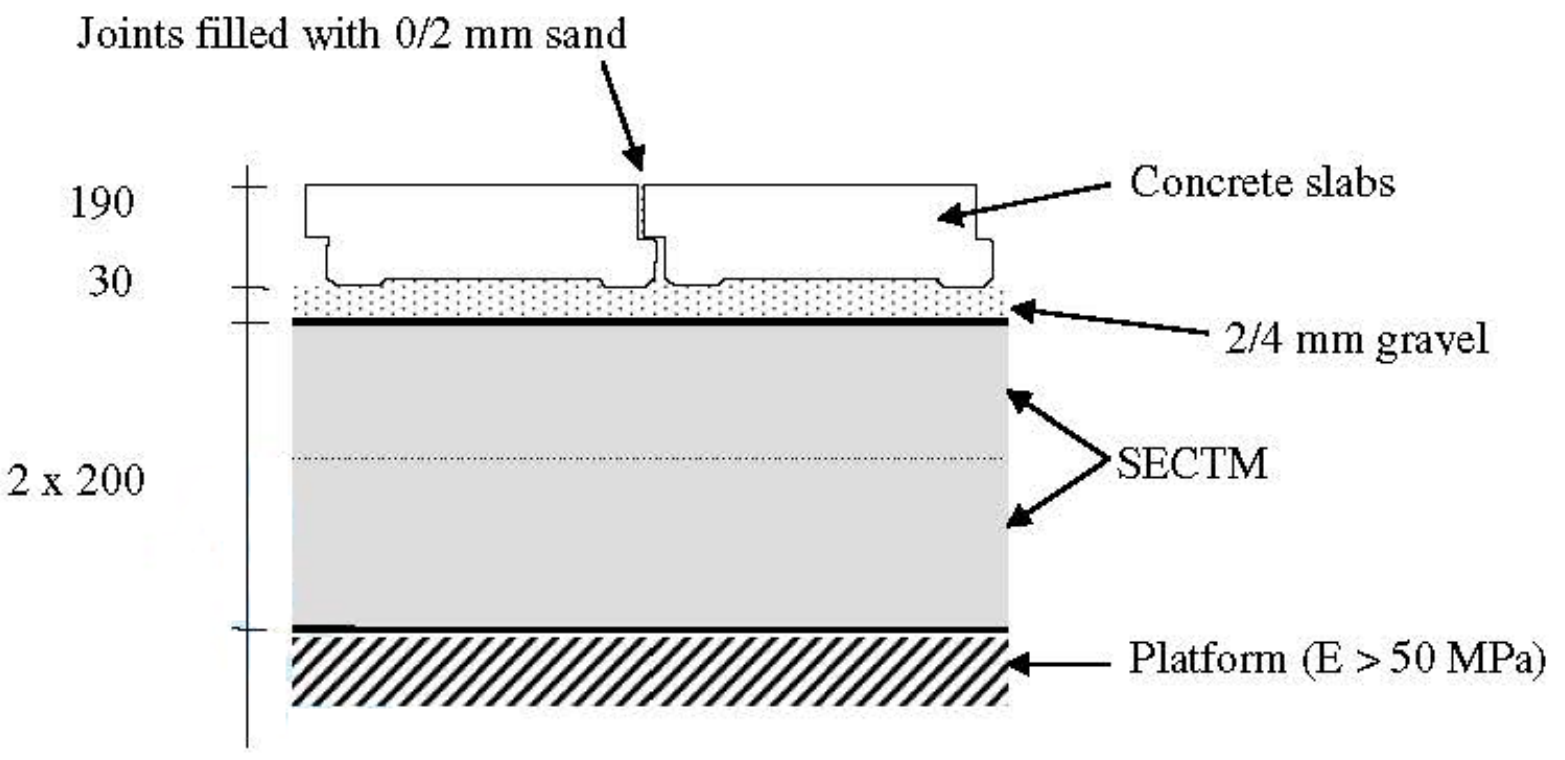

Figure 9: The Nantes RUP design (dimensions are expressed in mm)

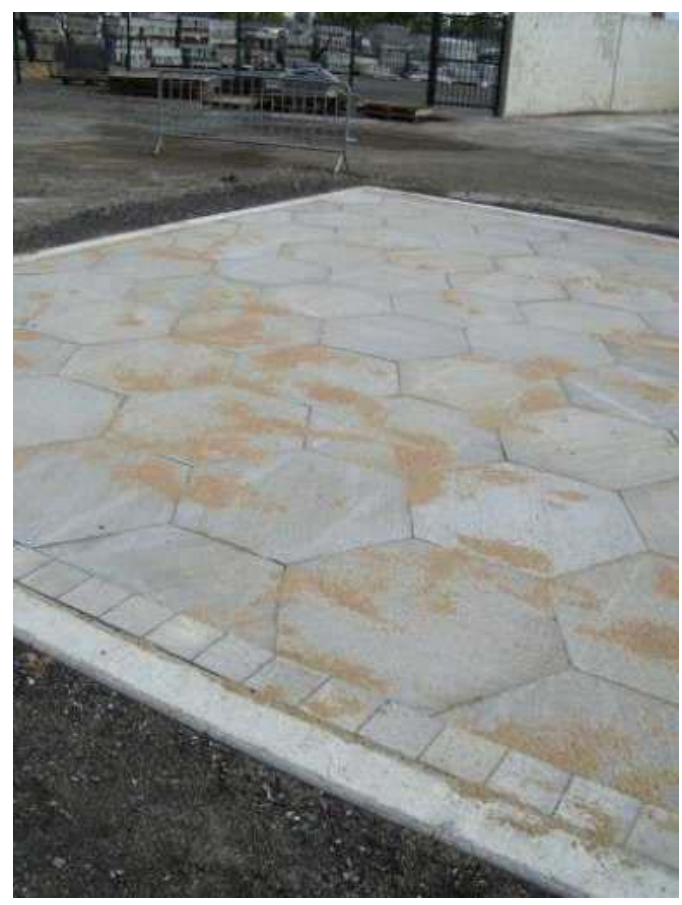

Figure 10: The Nantes RUP after completion (Note the pavers line along the pad edges.) 


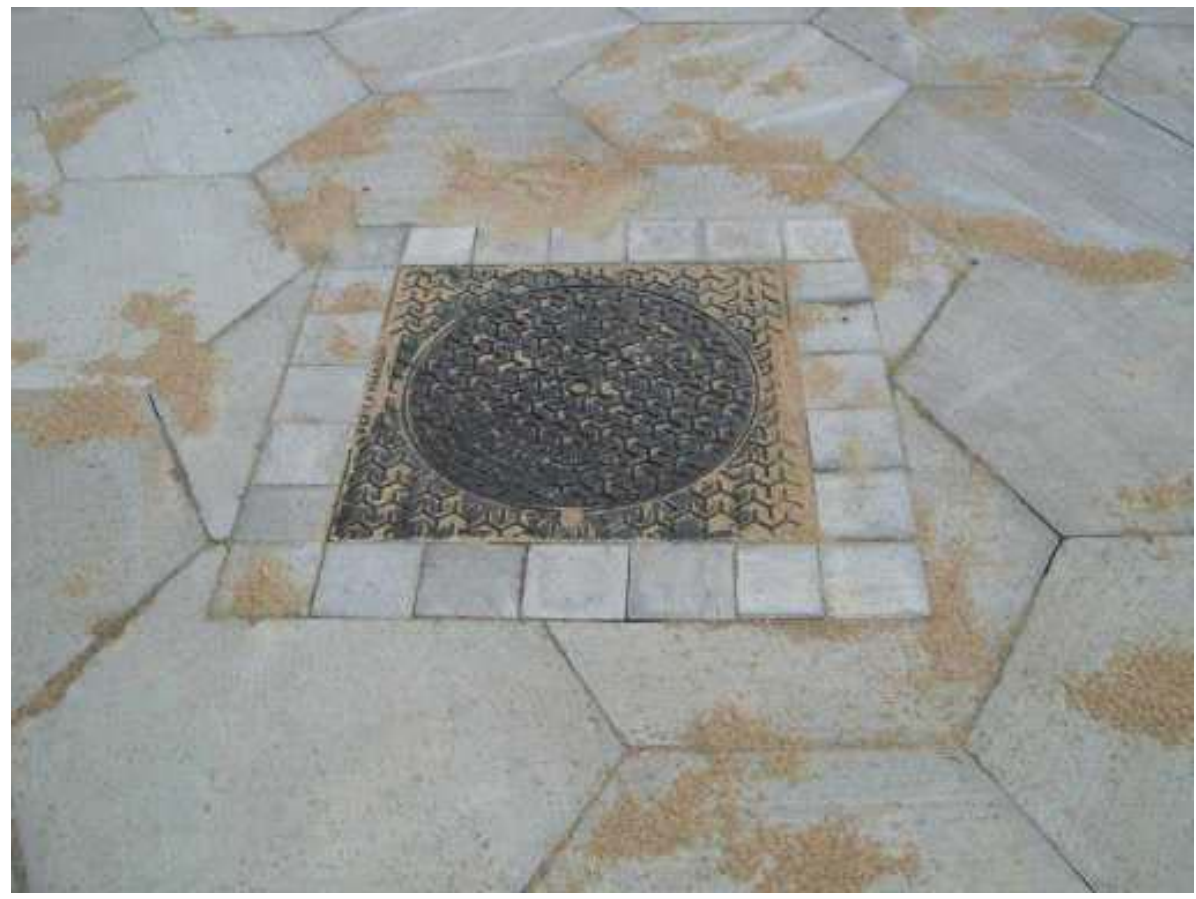

Figure 11: Fixed underground service outlet, surrounded by removable pavers and slabs

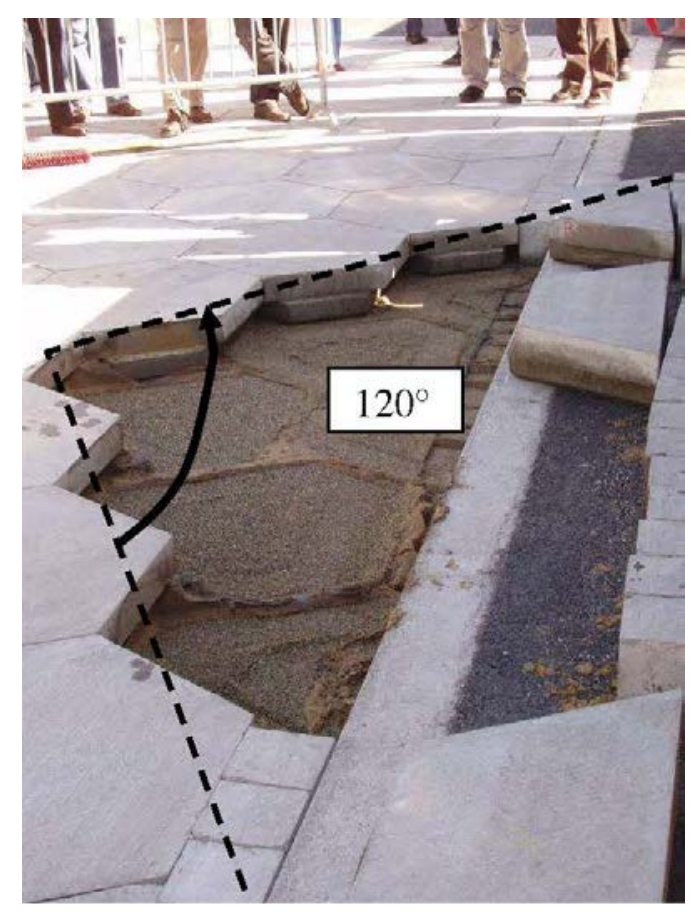

Figure 12: Removal of the connected RUP slab - All slabs within a $120^{\circ}$ dihedral must be removed in order to reach any inner point of the pad. 

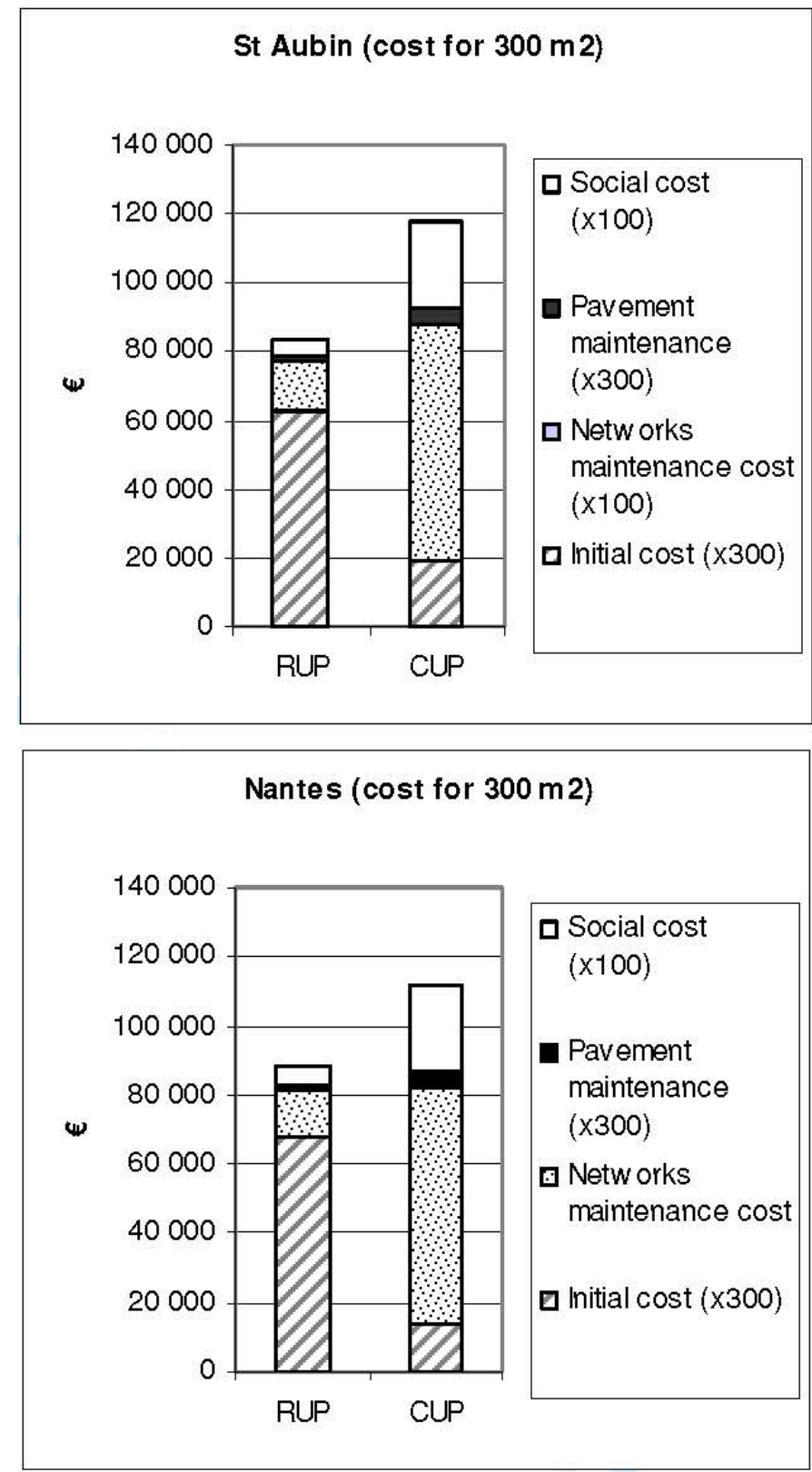

Figure 13: Comparative costs of an RUP (Removable Urban Pavement) vs. a CUP (Conventional Urban Pavement) 